PÁGINA ABERTA

\title{
A Educação no entardecer da vida
}

\author{
Aparecida da Silva Xavier Barros ${ }^{a}$ \\ Thelma Panerai Alves ${ }^{b}$ \\ Márcia Karina da Silva Luiz ${ }^{c}$ \\ Elicia Barros Guerra Souza ${ }^{d}$
}

\section{Resumo}

Nesse artigo, abordamos o acesso da população idosa à Educação Formal no Brasil, uma reflexão de grande importância, uma vez que ainda é bastante significativa a parcela dessa população que tem sido privada do bem simbólico que a Educação constitui. Trata-se de uma pesquisa de abordagem qualitativa, com coleta documental e bibliográfica de dados e de informações. Os resultados obtidos apontam que, com o aumento da expectativa de vida no país, cresce a necessidade de políticas e programas educacionais permanentes e presentes em todo o território nacional, que deem conta de atender às necessidades e às singularidades dos idosos.

Palavras-chave: Direito. Políticas. Educação. Vida. Pessoas Idosas.

\section{Introdução}

Sabemos que, na atualidade, a humanidade vivencia diversas transformações e, entre elas, o envelhecimento das populações, um fenômeno universal e irreversível que tem se acelerado. De acordo com a Organização Mundial de Saúde (OMS, 2015), a população mundial com mais de 60 anos vai passar dos atuais 841 milhões para 2 bilhões, até 2050 , sendo que $80 \%$ desses idosos viverão em países de renda baixa e média.

A população idosa brasileira segue também em crescimento. Segundo a Pesquisa Nacional por Amostra de Domicílios Contínua (Pnad-C), que além das características dos domicílios, investiga, regularmente, informações sobre sexo, idade e cor ou raça dos moradores, o país ganhou, entre 2012 e 2017, 4,8 milhões

\footnotetext{
a Instituto Federal da Paraíba, Campina Grande, PB, Brasil.

b Universidade Federal de Pernambuco, Recife, PE, Brasil.

c Universidade Federal Rural de Pernambuco, Recife, PE, Brasil.

d Universidade Federal de Pernambuco, Recife, PE, Brasil.

Recebido em: 01 set. 2019

Aceito em: 25 fev. 2021
} 
de idosos, atingindo a marca dos 30,2 milhões. Portanto, um crescimento de $18 \%$ desse grupo etário em 5 anos. As mulheres idosas são maioria expressiva nesse grupo, totalizando 16,9 milhões (56\%), enquanto os homens idosos são 13,3 milhões (44\%) (PARADELLA, 2018).

Ainda de acordo com o Instituto Brasileiro de Geografia e Estatística - IBGE (CLELIER, 2019), a partir de dados das Tábuas Completas de Mortalidade, a expectativa de vida dos brasileiros, ao nascer, alcançou 76,3 anos, em 2018. A maior longevidade foi esperada para as mulheres: 79,9 anos. Já a expectativa de vida, ao nascer, para os homens ficou em 72,8 anos. Para ambos os sexos, o estado com a maior esperança de vida ao nascer foi Santa Catarina: 79,7 anos. No outro extremo, os estados com a pior expectativa de vida foram o Maranhão, com a expectativa em 71,1 anos, e o Piauí, em 71,4 anos.

O processo de envelhecimento, porém, é complexo e envolve mudanças não lineares ou consistentes, que podem ser apenas vagamente associadas à idade de uma pessoa em anos (OMS, 2015). Nesse sentido, longe de ser vivenciada por todos os indivíduos da mesma maneira, a velhice caracteriza-se como um fenômeno de caráter diferenciado e singular (BEAUVOIR, 1990; MINAYO; COIMBRA JUNIOR, 2002; NERI, 2007), que "flutua de acordo com as épocas e as culturas" (SANT'ANNA, 2016, p. 12) e pode sofrer influências de variáveis derivadas: "do meio ambiente; das condições de trabalho; da classe social e do modo de vida" (ALVES JUNIOR, 2004, p. 61).

Em outras palavras, o envelhecimento não diz respeito apenas a uma questão biopsicológica, sendo, também, uma questão social (ANTUNES; ALMEIDA, 2019; PAPALÉO NETTO; CARVALHO FILHO; SALLES, 2006). Nesse ponto, é importante assinalar que, apesar do envelhecimento fazer parte do ciclo natural da vida (todos estão propensos a vivenciar a velhice), a sociedade geralmente vê as pessoas mais velhas por meio de formas estereotipadas, que levam ao ageismo $^{1}$, que pode ser uma forma ainda mais generalizada de discriminação do que o sexismo ou o racismo. Um exemplo de estereótipo de discriminação etária é o de que os idosos são dependentes ou são um fardo (OMS, 2015).

Diante desse cenário, a construção de um mundo mais favorável aos idosos é cada vez mais necessária, mas isso, segundo a OMS (2015), exige ações que, além de combater a discriminação etária, permitam a autonomia da pessoa idosa

O termo ageism (ageismo), que foi criado pelo médico americano Robert Neil Butler, em 1969, pode ser definido como "uma forma de intolerância relacionada com a idade, como forte preconceito e discriminação contra pessoas idosas" (SERRA, 2012, p. 36). 
e apoiem o envelhecimento saudável em todas as políticas e em todos os níveis de governo. No Brasil, os direitos dos idosos são assegurados pela Constituição Federal de 1988 e, também, por leis especiais. O direito à Educação ao longo da vida é um desses direitos afirmados na legislação, apesar de ser bastante negligenciado na prática (BRAGA; MAZZEU, 2017; HADDAD; DI PIERRO, 2000; MACHADO, 2016).

Não obstante o impacto positivo da Educação sobre a qualidade de vida dos idosos ser algo consensualmente aceito e destacado por vários autores (ANTUNES, 2017; CACHIONI; NERI, 2004; SANTOS et al., 2011; SILVA; GÜNTHER, 2000; UNICOVSKY, 2004), a legislação educacional brasileira costuma caracterizar o idoso como adulto. Contudo, quando assim procede, ignora as necessidades e as singularidades que esse sujeito apresenta (CACHIONI; TODARO, 2016; MOTT, 2016; SERRA; FURTADO, 2016).

Em vista dos argumentos apresentados, nesse artigo abordamos o acesso da população idosa à Educação formal no Brasil, uma reflexão de grande importância, uma vez que ainda é bastante significativa a parcela dessa população que tem sido privada do bem simbólico que a Educação constitui. Nesse sentido, nosso estudo apresenta uma abordagem qualitativa, com coleta documental e bibliográfica de dados e de informações (SEVERINO, 2016), sendo essas realizadas por meio de trabalhos acadêmicos, de estatísticas oficiais e dos principais marcos legais e normativos que afetaram a inclusão educacional do idoso no período pós-1988.

O presente texto está subdividido em quatro seções, sendo a primeira referente à introdução, onde expusemos a constituição do problema de pesquisa e o objetivo do trabalho. Na segunda seção, discorremos sobre a inserção dos idosos no contexto educativo, fazendo a articulação entre a legislação pertinente, aquilo que é necessário ser feito e a realidade. Na terceira seção, apontamos os principais contributos da escolarização na velhice. E, na quarta e última seção, apresentamos as considerações finais sobre o presente estudo.

\section{Da escola negada à escola (re)encontrada: embates entre o legal, o ideal e o real}

$\mathrm{O}$ acesso de jovens, adultos e idosos à Educação avançou lentamente ao longo da nossa história (BRAGA; MAZZEU, 2017; HADDAD; DI PIERRO, 2000; MACHADO, 2016). De acordo com dados da Pnad-C (NETO, 2018), a taxa de analfabetismo da população com 15 anos, ou mais, de idade no Brasil caiu de 7,2\% em 2016 para 7,0\% em 2017, mas não atingiu o índice de 6,5\% 
estipulado para 2015 pelo Plano Nacional de Educação (PNE) (BRASIL, 2014). Em números absolutos, a taxa representa 11,5 milhões de analfabetos. A Pnad-C revelou também outras desigualdades persistentes:

- A concentração de analfabetos foi maior na região Nordeste, que registrou a taxa de $14,5 \%$. O índice mais baixo, 3,5\%, foi registrado nas regiões Sul e Sudeste (Gráfico 1);

- A taxa de analfabetismo no grupo daqueles com 60 anos, ou mais, foi a maior nos dois anos analisados (2016 e 2017): 20,4\% e 19,3\%, respectivamente (Gráfico 2); e

- A taxa também atingiu mais que o dobro entre as pessoas que se declararam pretas ou pardas nos dois anos analisados: $9,9 \%$ e $9,3 \%$, respectivamente (Gráfico 3).

Gráfico 1 - Porcentagem de analfabetos por região do Brasil, em 2017

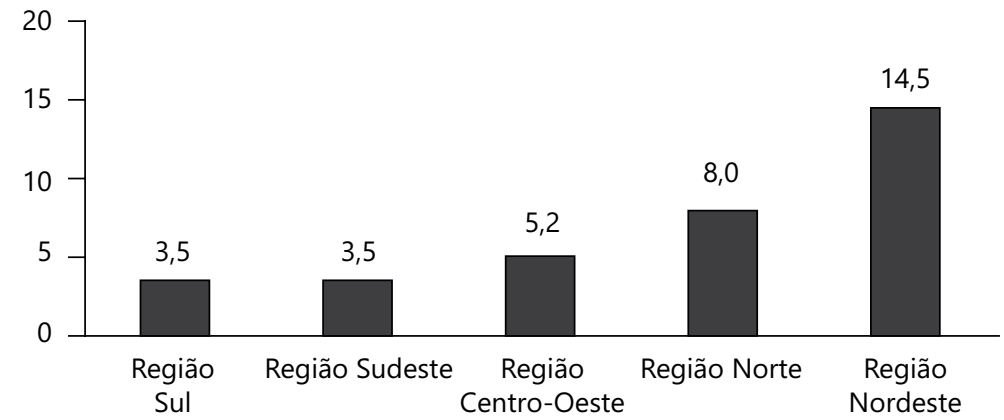

Fonte: Elaboração das autoras, a partir dos dados da Pnad-C (NETO, 2018).

Gráfico 2 - Taxas de analfabetismo entre diferentes faixas etárias - 2016 e 2017

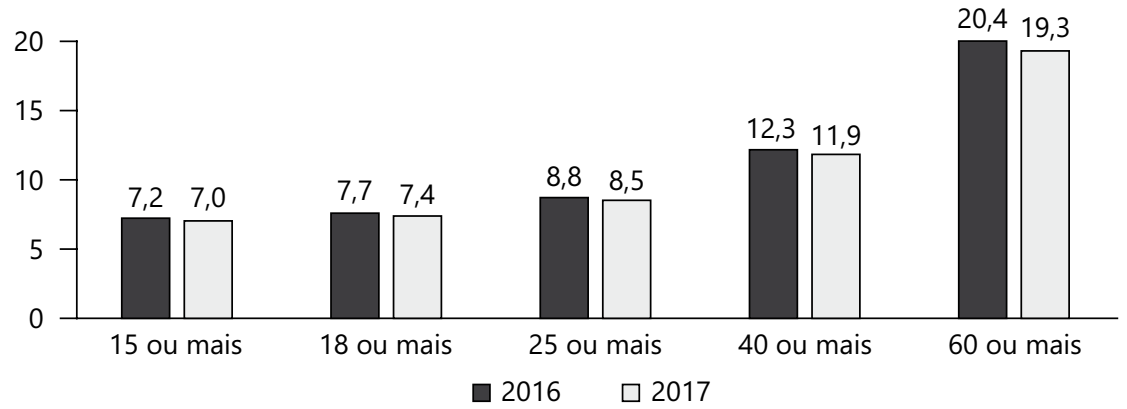

Fonte: Elaboração das autoras, a partir dos dados da Pnad-C (NETO, 2018). 
Gráfico 3 - Taxas de analfabetismo entre as populações branca e preta ou parda 2016 e 2017

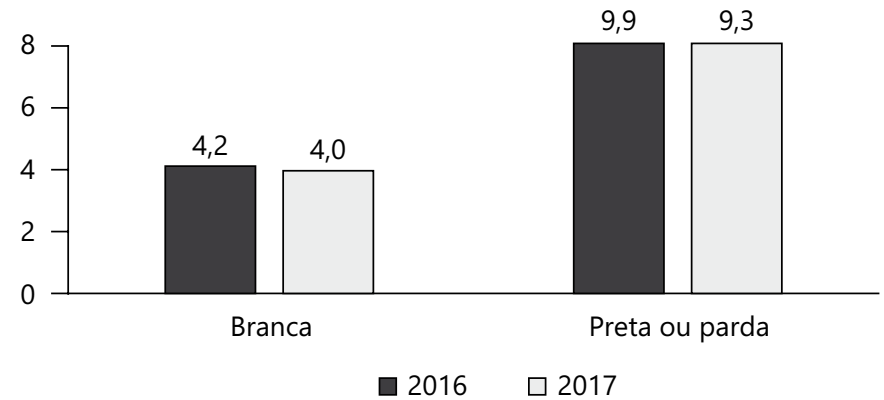

Fonte: Elaboração das autoras, a partir dos dados da Pnad-C (NETO, 2018).

Para a pesquisadora do IBGE Marina Aguas, coordenadora da pesquisa, três fatores influenciam a taxa de analfabetismo: 1) demografia: tanto a taxa de analfabetismo quanto a taxa de mortalidade são mais altas entre as pessoas mais velhas; 2) acesso ao serviço: as políticas públicas podem acelerar a redução das taxas ao garantir que pessoas de todas as faixas etárias sejam alfabetizadas e 3) faixas etárias fixas: como os grupos mais jovens são mais escolarizados, na medida em que eles ficam mais velhos e passam de uma faixa etária à seguinte, eles contribuem para a redução da taxa média de analfabetismo dessa faixa etária (MORENO, 2018).

Nesse cenário, em que os indicadores de escolaridade de alguns segmentos da população brasileira evidenciam progresso lento, mantendo significativa distância dos direitos assegurados na legislação, é imperativo que os esforços para reduzir os níveis de analfabetismo sejam redobrados, o que implica colocar de fato a alfabetização ${ }^{2}$, inclusive e, em especial, da população mais velha, na agenda política brasileira. Afinal, como afirmou Freire (1981, p. 15): "ninguém é analfabeto por eleição, mas como consequência das condições objetivas em que se encontra".

Nesse sentido, partindo de seu próprio conceito de analfabetismo, Freire (1981) esclareceu o que não é analfabetismo, para, em seguida, definir o que é: o analfabetismo não é uma "chaga" ou uma "erva daninha" a ser erradicada, tampouco uma enfermidade, mas uma das expressões concretas de uma realidade social injusta. Não se trata de um problema estritamente linguístico ou pedagógico, mas político (FREIRE, 1981). Para Borges (2016, p. 156), “a superação do analfabetismo

\footnotetext{
2 "O direito à alfabetização é parte inerente do direito à educação. É um pré-requisito para o desenvolvimento do empoderamento pessoal, social, econômico e político. A alfabetização é um instrumento essencial de construção de capacidades nas pessoas para que possam enfrentar os desafios e as complexidades da vida, da cultura, da economia e da sociedade" (UNESCO, 2010, p. 7).
} 
se apresenta como um dos maiores limites em termos de garantia do direito à educação". Portanto, são necessários efetivos esforços para que toda a população brasileira tenha acesso a esse bem cultural tão necessário para a vida moderna.

A Educação, "prática social, situada historicamente, numa determinada realidade" (DIAS; PINTO, 2019, p. 449), é um fator fundamental na formação humana em todas as idades, como testemunhou Freire (2013). Ele contou que foi alfabetizado no chão do quintal de sua casa, à sombra das mangueiras, com palavras do seu mundo de criança, deixando claro para o leitor que o contexto da educação vivido por ele na infância o influenciou significativamente durante toda a sua vida. Freire (2013) também mencionou a sua concepção de velhice e enfatizou que o idoso pode continuar aprendendo e interagindo com o mundo que o rodeia.

\subsection{EJA ou Ejai? Uma breve reflexão sobre a (in)visibilidade do idoso nessa modalidade de ensino}

O acesso ao ensino obrigatório e gratuito é direito público subjetivo, previsto no art. 208, $\S 1^{\circ}$ da Constituição Federal Brasileira de 1988 (BRASIL, 1988). Portanto, a sua titularidade é plena para todos, desde que queiram se valer dela. A Lei de Diretrizes e Bases da Educação Nacional (LDB), Lei no 9.394/1996 (BRASIL, 1996a), acompanha o preceito constitucional. Portanto, no que tange à Educação de Jovens e Adultos (EJA), afirma-se que:

Art. 37. A educação de jovens e adultos será destinada àqueles que não tiveram acesso ou continuidade de estudos nos ensinos fundamental e médio na idade própria e constituirá instrumento para a educação e a aprendizagem ao longo da vida (Redação dada pela Lei $\mathrm{n}^{\mathrm{o}} 13.632$, de 2018).

$\S 1^{\circ}$ Os sistemas de ensino assegurarão gratuitamente aos jovens e aos adultos, que não puderam efetuar os estudos na idade regular, oportunidades educacionais apropriadas, consideradas as características do alunado, seus interesses, condições de vida e de trabalho, mediante cursos e exames (BRASIL, 1996a).

Nesse sentido, a LDB, apesar de não mencionar o idoso, reconhece e garante o acesso desse sujeito aos estudos e sua continuidade durante a Educação obrigatória. Em outro documento, o Parecer do Conselho Nacional de Educação (CNE)/ Câmara de Educação Básica (CEB) nº 11/2000, que trata das Diretrizes Curriculares 
Nacionais para a EJA, o idoso é citado, mas também como integrante de uma faixa etária sob a noção de adulto. Nessa linha, conforme o Parecer: "adulto é o ente humano já inteiramente crescido. $\mathrm{O}$ estado de adulto (adultícia) inclui o idoso" (BRASIL, 2000a, p. 7).

Nesse contexto, é importante frisar que a própria nomenclatura da EJA, durante muito tempo, não demarcou o lugar do estudante idoso (DINIZ; SCOCUGLIA; PRESTES, 2010). O emprego da sigla EJAI, Educação de Jovens, Adultos e Idosos, é relativamente recente entre nós, tendo sido introduzido no Brasil a partir das discussões nacionais e internacionais que concebem a Educação ${ }^{3}$ e a aprendizagem ${ }^{4}$ como um processo que se dá ao longo da vida.

Para Serra e Furtado (2016), a inclusão escolar dos idosos ainda é um desafio. Portanto, segundo os autores, não é suficiente substituir a sigla EJA por EJAI, sendo preciso garantir efetivamente o acesso e a continuidade à Educação ao longo da vida, dando visibilidade aos idosos no cenário educativo. Nessa perspectiva, e levando em conta as peculiaridades e as diversidades do coletivo dos idosos, Cachioni e Todaro (2016) asseveram:

É um lamentável equívoco considerar a educação de idosos na mesma perspectiva utilizada em outras etapas da vida. Os programas educacionais para idosos devem ter como ponto de partida conhecimentos específicos sobre as características desse sujeito, que possui peculiaridades garantidas pelo seu próprio desenvolvimento e experiências acumuladas, algo que lhes confira autonomia para decidir o que, como e quando desejam aprender (p. 182).

Complementando essa abordagem, destacamos que "a educação é um fator fundamental na formação crítica do idoso, é função determinante para que ele tenha qualidade de vida e condições de se manter ativo e consciente da sua própria velhice" (MOTT, 2016, p. 259). Dessa maneira, é necessário que ele não se sinta excluído. Na compreensão de Peres (2005, p. 22), "a exclusão da velhice da esfera produtiva justifica a sua exclusão, também, do sistema educativo". Segundo o

\footnotetext{
Sob a perspectiva da Educação Popular, a educação ao longo da vida "valoriza exatamente o tema 'vida' como pilar da educação. Portanto, entende a educação não como um processo formal, burocrático, cartorial, mas ligado essencialmente à vida cotidiana, ao trabalho, à cultura, valorizando processos formais e não formais. Trata-se de uma educação como um processo ligado à vida, ao bem viver das pessoas, à cidadania" (GADOTTI, 2016, p. 62).

4 A VI Conferência Internacional de Educação de Adultos (VI Confitea) definiu que: "aprendizagem ao longo da vida, 'do berço ao túmulo', é uma filosofia, um marco conceitual e um princípio organizador de todas as formas de educação, baseada em valores inclusivos, emancipatórios, humanistas e democráticos, sendo abrangente e parte integrante da visão de uma sociedade do conhecimento" (UNESCO, 2010, p. 6).
} 
autor, a sociedade capitalista estruturou os sistemas produtivo e educacional com base em seus interesses.

A criança deve ser educada para que, quando adulta, venha a ser um trabalhador adequado às necessidades do capital. O jovem e o adulto devem ser formados e profissionalizados para assumir uma função específica dentro da esfera produtiva e garantir assim a eficiência do sistema econômico em constante desenvolvimento e mudança. E o velho? Onde entra? A verdade é dura e cruel: não há lugar para o velho na sociedade capitalista, conforme lembram Simone de Beauvoir (1990) e Ecléa Bosi (1994) (PERES, 2005, p. 22).

Sob esse prisma, Peres (2005) ressalta que:

a ausência de um projeto educativo para a velhice na sociedade capitalista fundamenta-se tanto na ausência de interesse do sistema produtivo para com os trabalhadores que envelhecem, quanto na pressuposição de que tais trabalhadores já foram devidamente disciplinados ao longo da sua vida produtiva e que, por isso, não representam mais uma ameaça à ordem vigente. São tidos, na realidade, como um peso morto dentro do sistema, e que deve ser mantido em sobrevida por uma renda miserável de aposentadoria, a qual se torna cada vez mais comprimida em todo o mundo em virtude do chamado déficit previdenciário (PERES, 2005, p. 23).

Cabe destacar, com base na literatura, que a negação recorrente do direito à Educação aos idosos, materializada, especialmente, na reduzida oferta de Educação formal, na falta de recursos didáticos etc., tem contribuído para a permanência dos elevados índices de analfabetismo ${ }^{5}$ e de baixa escolaridade em nosso país, bem como evidenciado a crescente situação de abandono e de precarização da EJA.

\subsection{A Educação dos idosos nos documentos legais, diretrizes e programas educacionais no período pós-1988}

A inserção dos idosos no contexto educativo no período pós-1988 - expressa nos principais marcos legais e normativos da/para EJA: Constituição Federal (BRASIL,

\footnotetext{
"O analfabetismo continua fora da agenda política. Parece que cansamos de alfabetizar adultos. É a política da desistência. Não respeitando a biografia dos analfabetos adultos, tentamos 'letrá-los' e não conseguimos. Então, coloca-se a culpa nos próprios analfabetos. Eles são inalfabetizáveis!" (GADOTTI, 2016, p. 67).
} 
1988), LBD (BRASIL, 1996a), Fundo de Manutenção e Desenvolvimento do Ensino Fundamental e Valorização do Magistério - Fundef (BRASIL, 1996b), Parecer CNE/CEB $n^{\circ} 11$ (BRASIL, 2000a), Resolução CNE/CEB n ${ }^{\circ} 1$ (BRASIL, 2000b), Estatuto do Idoso (BRASIL, 2003), Fundo de Desenvolvimento e Manutenção da Educação Básica e de Valorização dos Profissionais da Educação - Fundeb (BRASIL, 2007) e Plano Nacional de Educação (BRASIL, 2014) -, foi, e ainda é, um processo difícil, caracterizado por conquistas e retrocessos.

As políticas educacionais mais expressivas relacionadas à EJA tiveram início com a Constituição Federal de 1988 (HADDAD; DI PIERRO, 2000), que garantiu à população jovem e adulta o direito à Educação fundamental, responsabilizando o Estado pela oferta universal e gratuita desse nível de ensino a todos que a ele não tiveram acesso e progressão na infância e adolescência.

Art. 208. O dever do Estado com a Educação será efetivado mediante a garantia de:

I - Educação básica obrigatória e gratuita dos 4 (quatro) aos 17 (dezessete) anos de idade, assegurada inclusive sua oferta gratuita para todos os que a ela não tiveram acesso na idade própria (BRASIL, 1988).

Uma questão, porém, merece ser considerada a partir dessa conquista: o entendimento de que há uma "idade própria" para a escolarização. Como salienta Gadotti (2016), a expressão "idade própria" criou o mito de que existe uma idade "correta" ou "adequada" para se aprender, gerando, assim, o preconceito contra os que não conseguiram alfabetizar-se na referida idade. Nesse contexto, as salas de alfabetização e a própria EJA costumam ser vistas como "depósitos" dos excluídos, cuja função é compensar a escolaridade "perdida". Visão bem diferente daquela que concebe essa escolarização como uma oportunidade para jovens, adultos e idosos recuperarem um direito que tiveram negado (FREIRE, 1981).

Di Pierro (2005), apoiada no estudo de Oliveira (1999), diz que a psicologia do desenvolvimento humano não mais sustenta a ideia de que exista uma idade apropriada para aprender: "as pesquisas demonstram que a aprendizagem ocorre em qualquer idade, ainda que a pertinência a determinados grupos socioculturais ou etários possa estar relacionada à variância nas funções, características e estilos cognitivos" (DI PIERRO, 2005, p. 1119). 
Nesse sentido, conforme esclarecido por Pinto (2005), tudo foi pensado como se o sistema capitalista não pré-determinasse a condição de exclusão de algumas categorias de pessoas, mesmo aquelas que tiveram o direito à Educação garantido na Carta Magna (BRASIL, 1988).

Uma lei do desenvolvimento educacional é esta: a sociedade nunca desperdiça seus recursos educacionais (econômicos e pessoais), apenas proporciona educação nos estritos limites de suas necessidades objetivas. Não educa ninguém que não precise educar (PINTO, 2005, p. 102-103).

A LDB (BRASIL, 1996a), diz que "apesar de reconhecer o direito à EJA, deixou de lado uma série de iniciativas importantes à realização plena desse direito" (PORCARO, 2011, p. 32). Além disso, com a aprovação do Fundef (BRASIL, 1996b), Lei 9.424/1996, “o ensino de jovens e adultos passou a concorrer com a Educação infantil no âmbito municipal e com o Ensino Médio no âmbito estadual pelos recursos públicos não capturados pelo Fundef" (HADDAD; DI PIERRO, 2000, p. 123).

Há, no entanto, que se reconhecer que, se por um lado, ao focalizar o investimento público no ensino de crianças e de adolescentes de 7 a 14 anos, o Fundef contribuiu para que o Ensino Fundamental se aproximasse da universalização para essa população; por outro, não foi acompanhado um progresso similar dos demais grupos de alunos. Por essa razão, tendo em vista aquela realidade, a Educação brasileira, norteada por uma visão sistêmica, ainda precisa mobilizar esforços concomitantes para atender de forma equânime todos os níveis e modalidades de Educação e ensino, seja procurando assegurar e expandir o acesso, quando necessário, seja ampliando o investimento, de modo que cada um deles desfrute do caráter de prioridade que possui.

Aqui, abrimos um parêntese para falar que a inscrição da EJA no Fundeb, Lei 11.494/2007, realizou-se de forma progressiva e, também, em condições desfavoráveis (DI PIERRO; HADDAD, 2015), haja vista que, mesmo contemplando todas as etapas e modalidades que compõem a Educação básica, o que favoreceu à EJA, o Fundeb não foi uma medida suficiente e os entes federados continuaram a investir percentuais muito baixos de seus recursos educacionais nessa modalidade de Educação (CARVALHO, 2014).

Além disso, o Fundeb atribuiu à EJA uma importância menor em relação às demais modalidades de ensino, ou seja, o fator de ponderação atribuído à EJA, na época, 
foi de $15 \%$ dos recursos do fundo em cada unidade da Federação e a fixação do fator de ponderação atribuído à modalidade, de 0,7 no ano de implantação, foi a menor dentre todas as etapas e as modalidades da Educação básica. Assim, de um lado, o Fundeb esbarrou na política macroeconômica do governo, que continuou priorizando o equilíbrio fiscal em detrimento do financiamento das políticas sociais, e, de outro, alimentou conflitos de interesses entre estados e municípios com relação ao investimento nos níveis e nas modalidades de ensino de respectiva responsabilidade. Carvalho (2014) chamou a atenção para o fato de que, mesmo recebendo recursos por estudantes matriculados na EJA, muitos governantes, municipais ou estaduais, continuaram renegando a escolarização a outros jovens e adultos ${ }^{6}$.

Conforme pontuou Haddad (2002), uma análise mais aprofundada da LDB (BRASIL,1996a) permite considerar que ela incorporou uma importante mudança conceitual ao substituir a denominação Ensino Supletivo por EJA, alteração elogiada por profissionais da área, mas, contraditoriamente, no artigo 38, referenciou os exames supletivos, reafirmando a suplência ${ }^{7}$ enquanto compensação e correção de escolaridade. As idades mínimas de 15 anos para o Ensino Fundamental e de 18 anos para o Ensino Médio corroboram esta falha, privilegiando a idade e a certificação em detrimento dos processos pedagógicos.

Dando continuidade ao debate, merece destaque o Parecer CNE/CEB n ${ }^{\circ}$ 11/2000, relatado por Carlos Roberto Jamil Cury, a partir do qual foi publicada a Resolução CEB/CNE n ${ }^{\circ}$ 01/2000, que estabelece as Diretrizes Curriculares Nacionais para a EJA. Pela primeira vez foi pensada uma proposta pedagógica para a modalidade. $\mathrm{O}$ intuito era que ela servisse como subsídio à elaboração de projetos e de propostas curriculares a serem desenvolvidos por organizações governamentais e não governamentais, adaptados às realidades locais e às necessidades específicas.

O Parecer CNE/CEB n ${ }^{\circ}$ 11/2000 (BRASIL, 2000a) atribuiu à EJA a função de reparação da dívida social resultante da história excludente do nosso país.

\footnotetext{
6 Carvalho (2014) levou em conta a redução no número das matrículas na EJA pós-Fundeb. Dados do Censo Escolar 2016 mostraram redução de matrículas da EJA em todas as etapas de ensino no período 2008 - 2016 : nos anos iniciais do Ensino Fundamental as matrículas despencaram de 1.127.077, em 2008, para 628.393, em 2016; nos anos finais, a queda foi de 2.164.187 para 1.356.141, respectivamente; e, no Ensino Médio, de 1.635.245 para 1.341.841, a menor baixa. Crescimento de matrículas só na Educação profissional, que partiu de 18.915, em 2008, para 95.752, em 2016 (INEP, 2017).

Aprovada em plena ditadura militar, a "doutrina do ensino supletivo" não incorporou as ricas contribuições que os movimentos de Educação e cultura popular legaram à Educação de adultos (difundidas especialmente em todo o mundo pela obra de Paulo Freire). Ao contrário, atendeu ao apelo modernizador da Educação a distância e aderiu aos preceitos tecnicistas da individualização da aprendizagem e da instrução programada (DI PIERRO, 2005).
} 
A inclusão, portanto, se configurou como a ideia central da função reparadora. Ela foi apresentada no Parecer como propiciadora do ingresso no mercado de trabalho. Nessa perspectiva, buscou-se, por meio da inclusão no sistema educacional daqueles que estavam fora da escola, a inclusão na vida cidadã e, com ela, o acesso ao mercado de trabalho. Pode-se inferir, de acordo com esse documento, que, para tornar-se cidadão, é imprescindível estar inserido no mundo produtivo.

A esse respeito, Silva Júnior (2002) esclarece que, no processo de mundialização do capital, a cidadania é uma cidadania produtiva, ou seja, é vinculada ao processo de trabalho e subordinada aos interesses do capital. Logo, a partir da ideia apresentada no Parecer CEB n ${ }^{\circ}$ 11/2000 acerca da inclusão de jovens e de adultos na sociedade, ou seja, no mercado, a cidadania só poderia ser alcançada via investimento pessoal: aquisição das competências sociais e cognitivas que caracterizam um perfil profissional desejado pela sociedade (FRIEDRICH et al., 2010).

Assim, ao mesmo tempo em que transfere para o indivíduo a responsabilidade por adquirir a capacidade de incluir-se ou não no mercado de trabalho (FRIGOTTO, 1996; SAVIANI, 2013), pavimenta-se a ideia de que a Educação escolar não garante o acesso ao emprego, mas apenas "a conquista do status de empregabilidade" (SAVIANI, 2013, p. 430). "A ênfase na qualificação profissional da mão de obra marca também a abordagem conferida à EJA no segundo Plano Nacional de Educação (PNE)" (DI PIERRO; HADDAD, 2015, p. 213).

Sobre o PNE, Serra e Furtado (2016) afirmam que o documento não demonstra explicitamente uma política pública específica para os idosos. Nesse sentido, apesar de definir no artigo $2^{\circ}$, Inciso I, a erradicação do analfabetismo, e no Inciso II, a universalização do atendimento escolar, "não expressa grande preocupação e prioridade ao maior percentual de analfabetos que estão na faixa etária a partir de 60 anos" (SERRA; FURTADO, 2016, p. 158).

Próximo de completar 20 vinte anos do Estatuto da Pessoa Idosa, Lei $\mathrm{n}^{\circ} 10.741 / 2003$ (BRASIL, 2013), muito falta ainda para implementar os artigos 20 a 25 na vida dos idosos brasileiros. Concluímos, então, que esse paradigma que prioriza processos de certificação dos trabalhadores em detrimento do acesso ao conhecimento, atribuindo à EJA um sentido apenas compensatório, não serve para a Educação de idosos. Acreditamos que a Educação capaz de responder às necessidades desses sujeitos não é essa, mas aquela entendida 
enquanto projeto de humanização e de transformação, como nos ensinou Freire (1981; 1987; 2011).

\section{Contributos da intervenção educativa junto à população idosa}

Diversos estudos têm discutido a importância da Educação para o desenvolvimento do bem-estar dos idosos. Silva e Günther (2000) afirmam que

a falta de escolarização traz grande prejuízo para o desenvolvimento dessas pessoas. A escolarização favorece a situação econômica e fornece recursos para que o indivíduo possa preparar-se melhor para envelhecer e compensar as perdas decorrentes do processo. É imprescindível que políticas de educação sejam implementadas para beneficiar os adultos que não tiveram acesso à escola e para evitar que outras pessoas fiquem na mesma situação, no futuro (p. 38).

Unicovsky (2004) considera que a Educação pode contribuir para que os idosos consigam vencer os desafios impostos pela idade e pela sociedade, "propiciandolhes o aprendizado de novos conhecimentos e oportunidades para buscar seu bem-estar físico e emocional" (UNICOVSKY, 2004, p. 241).

Cachioni e Neri (2004, p. 48) esclarecem que "na frequência aos bancos escolares, os idosos têm chance de encontrar alternativas dinâmicas de autodesenvolvimento e atualização". Na mesma direção, Santos et al. (2011) apontam que a inserção de idosos em programas educacionais facilita o acesso ao conhecimento com autonomia e a conquista de melhor qualidade de vida.

De forma análoga, Mott (2016, p. 259) destaca que "a educação é um fator fundamental na formação crítica do idoso, é função determinante para que ele tenha qualidade de vida e condições de se manter ativo e consciente da sua própria velhice".

Acerca da necessidade da Educação, Cachioni e Todaro (2016) pontuam que, entre os idosos, a procura pela escola está relacionada

à realização de uma vontade antiga de aprender os conteúdos escolares. Saber ler e escrever é uma condição frequentemente associada a ter uma vida melhor. A influência da escolaridade de filhos e netos é outro fator que impulsiona os mais velhos a 
estudar. É comum o desejo de auxiliar na lição de casa das crianças ou participar mais ativamente da educação delas. A busca por independência é outra razão. Não precisar mais de vizinhos ou familiares para ler documentos ou identificar as informações em rótulos dos produtos, entre outras atividades em que a leitura é necessária, é comumente citado. Com o tempo, as expectativas se ampliam. As justificativas para continuar são várias e estão ligadas, sobretudo, às conquistas relacionadas à escola. Sentir-se mais seguro para comentar os acontecimentos atuais, ver beleza na letra de uma música, fazer amigos e se sentir parte de um grupo social, são exemplos. Estudar, para esse grupo, segundo Coura (2007), significa, principalmente, a chance de alargar horizontes (p. 177).

O estudo de Antunes (2017), corrobora as ideias dos anteriores e aponta para a necessidade de se repensar o envelhecimento, que "não é mais percepcionado como um tempo de aposentadoria e inatividade e, nesse sentido, uma fase vazia de sentido e significados, uma fase cinzenta e acabada" (p. 166).

\section{Considerações finais}

Concluímos enfatizando que um importante desafio que se coloca à Educação, na atualidade, é o de preparar os adultos e os idosos para a fase em que as condições de vida sofrem alterações muito profundas: a velhice. Por essa ótica, acreditamos que essa etapa da vida também pode ser um período de maior conhecimento da própria velhice, de valorização da experiência acumulada e de desenvolvimento de novos projetos de vida.

A Educação no entardecer da vida concretiza-se, fundamentalmente, na transformação dos tempos livres em tempos de Educação e de aprendizagem. Nesse sentido, as iniciativas que priorizam a Educação são também oportunidades para que o idoso continue seu percurso de desenvolvimento por meio do acesso ao conhecimento, à formação e à cultura.

Nessa assertiva, as intervenções educativas devem constituir-se um instrumento a serviço das necessidades e interesses dos idosos, explorando o repertório de conhecimentos por eles já adquiridos, bem como fazendo da história de vida desses sujeitos o referencial para o despertar e a compreensão de problemas, instigando-os à busca de conhecimentos e de soluções. Nesse ponto, é imprescindível a organização dos currículos, das práticas e dos recursos educacionais da EJA, de modo que propiciem aos idosos a oportunidade de aquisição e de atualização de conhecimentos e fortalecimento do convívio social. 


\section{Education in the evening of life}

\section{Abstract}

In this article, we address the access of the elderly population to formal Education in Brazil, a reflection of great importance, since it is still quite significant the portion of this population that has been deprived of the symbolic good that education constitutes. This is a qualitative approach research, with documentary and bibliographic data and information collection. The results obtained indicate that, with the increase in life expectancy in the country, grows the need for permanent and present educational policies and programs throughout the national territory, which address the needs and singularities of the elderly.

Keywords: Law. Politics. Education. Life. Elderly people.

\section{La Educación en la atardecer de la vida}

\section{Resumen}

En este artículo abordamos el acceso de la población anciana a la Educación formal en Brasil, una reflexión de gran importancia, ya que la porción de esta población que se ha visto privada del bien simbólico que constituye la Educación es todavía bastante significativa. Se trata de una investigación de abordaje cualitativo, con recogida documental y bibliográfica de datos e información. Los resultados obtenidos muestran que, con el aumento de la esperanza de vida en el país, existe una creciente necesidad de politicas y programas educativos permanentes en todo el territorio nacional, que sean capaces de atender las necesidades y singularidades de las personas mayores.

Palabras clave: Derecho. Politicas. Educación. Vida. Personas Mayores. 


\section{Referências}

ALVES JUNIOR, E. D. A pastoral do envelhecimento ativo. Tese (Doutorado em Educação Física) - Universidade Gama Filho, Rio de Janeiro, 2004.

ANTUNES, M. C. Educação e bem-estar na terceira idade. Revista Kairós Gerontologia, São Paulo, v. 20, n. 1, p. 155-170, 2017. https://doi.org/10.23925/2176-901X.2017v20i1p155-170

ANTUNES, M. C.; ALMEIDA, N. Envelhecer com sucesso: contributos da Educação. Revista Kairós Gerontologia, São Paulo, v. 22, n. 1, p. 81-107, 2019. https://doi.org/10.23925/2176-901X.2019v22i1p81-107

BEAUVOIR, S. A velhice. Rio de Janeiro: Nova Fronteira, 1990.

BORGES, L. Alfabetização de jovens e adultos na perspectiva da educação ao longo da vida. In: NACIF, P. G. S. et al. (org.). Confintea Brasil +6: tema central e oficinas temáticas. Brasília, DF: MEC, 2016. p. 153-161. (Coletânea de textos).

BRAGA, A. C.; MAZZEU, F. J. C. O analfabetismo no Brasil: lições da história. Revista On Line de Política e Gestão Educacional, Araraquara, v. 21, n. 1, p. 24-46, jan./abr., 2017. https://doi.org/10.22633/rpge.v21.n.1.2017

BRASIL. Senado Federal. Constituição da República Federativa do Brasil de 1988. Brasília, DF: Senado Federal, 1988.

BRASIL. Lei $\mathrm{n}^{\circ}$ 9.394, de 20 de dezembro de 1996. Estabelece as diretrizes e bases da educação nacional. Diário Oficial da União, Brasília, DF, 23 dez. 1996a.

BRASIL. Lei $\mathrm{n}^{\circ}$ 9.424, de 24 de dezembro de 1996. Dispõe sobre o Fundo de Manutenção e Desenvolvimento do Ensino Fundamental e de Valorização do Magistério. Diário Oficial da União, Brasília, DF, 26 dez. 1996b.

BRASIL. Lei $\mathrm{n}^{\circ} 10.741$, de 1 de outubro de 2003. Dispõe sobre o Estatuto do Idoso e dá outras providências. Diário Oficial da União, Brasília, DF, 3 out. 2003.

BRASIL. Lei no 11.494, de 20 de junho de 2007. Regulamenta o Fundo de Manutenção e Desenvolvimento da Educação Básica e de Valorização dos Profissionais da Educação - FUNDEB, de que trata o art. 60 do Ato das Disposições Constitucionais Transitórias; altera a Lei n o 10.195, de 14 de fevereiro de 2001; revoga dispositivos das Leis n os 9.424, de 24 de dezembro de 1996, 10.880, de 9 de junho de 2004, e 10.845, de 5 de março de 2004; e dá outras providências. 
Diário Oficial da União, ed. 118, seção 1, Brasília, DF, p. 7, 21 de jun. 2007.

BRASIL. Lei no 13.005 , de 25 de junho de 2014. Plano Nacional de Educação - PNE. Diário Oficial da União, Brasília, DF, 26 jun. 2014.

BRASIL. Conselho Nacional de Educação. Parecer CNE 11/2000. Diretrizes Curriculares Nacionais para a Educação de Jovens e Adultos. Brasília, DF: CNE, 2000a.

BRASIL. Conselho Nacional de Educação. Resolução CNE/CEB n ${ }^{\circ} 1$ de 2000. Diretrizes Curriculares Nacionais para a Educação de Jovens e Adultos. Brasília, DF: CNE, 2000b.

CACHIONI, M.; NERI, A. L. Educação e velhice bem-sucedida no contexto das universidades da terceira idade. In: NERI, A. L.; YASSUDA, M. S. (orgs.). Velhice bem-sucedida: aspectos afetivos e cognitivos. 2. ed. Campinas: Papirus, 2004. p. 29-49.

CACHIONI, M.; TODARO, M. A. Política nacional do idoso: reflexão acerca das intenções direcionadas à Educação formal. In: ALCÂNTARA, A. O.; CAMARANO, A. A.; GIACOMIN, K. C. (orgs.). Politica Nacional do Idoso: velhas e novas questões. Rio de Janeiro: IPEA, 2016. p. 175-198.

CARVALHO, M. P. O financiamento da EJA no Brasil: repercussões iniciais do FUNDEB. Revista Brasileira de Política e Administração da Educação. Brasília, DF, v. 30, n. 3, p. 635-655, set./dez. 2014. https://doi.org/10.21573/vol30n32014.57618

CLELIER, C. Expectativa de vida dos brasileiros aumenta para 76,3 anos em 2018. Agência IBGE Notícias. 28 nov. 2019. Disponível em: https://agenciadenoticias.ibge.gov.br/agencia-noticias/2012-agencia-denoticias/noticias/26103-expectativa-de-vida-dos-brasileiros-aumenta-para-763-anos-em-2018. Acesso em: 11 dez. 2019.

DIAS, E.; PINTO, F. C. F. Educação e sociedade. Ensaio: Avaliação e Políticas Públicas em Educação, Rio de Janeiro, v. 27, n. 104, p. 449-454, set. 2019. https://doi.org/10.1590/s0104-40362019002701041

DINIZ, A.; SCOCUGLIA, A.; PRESTES, E. (orgs.). A aprendizagem ao longo da vida e a educação de jovens e adultos: possibilidades e contribuições ao debate. João Pessoa: Editora Universitária da UFPB, 2010. 
DI PIERRO, M. C. Notas sobre a redefinição da identidade e das políticas públicas de Educação de jovens e adultos no Brasil. Educação e Sociedade, Campinas, v. 26, n. 92, p. 1115-1139, out. 2005. https://doi.org/10.1590/S0101-73302005000300018

DI PIERRO, M. C.; HADDAD, S. Transformações nas políticas de Educação de Jovens e Adultos no Brasil no início do terceiro milênio: uma análise das agendas nacional e internacional. Cadernos Cedes, Campinas, v. 35, n. 96, p. 197-217, maio-ago., 2015. https://doi.org/10.1590/CC0101-32622015723758

FREIRE, P. À sombra desta mangueira. 11. ed. Rio de Janeiro: Paz e Terra, 2013.

FREIRE, P. Ação Cultural Para a Liberdade e outros escritos. 5.ed. Rio de Janeiro: Paz e Terra, 1981.

FREIRE, P. Pedagogia do oprimido. 17. ed. Rio de Janeiro: Paz e Terra, 1987.

FREIRE, P. Pedagogia da autonomia: saberes necessários à prática educativa. 43. ed. São Paulo: Paz e Terra, 2011.

FRIEDRICH, M. et al. Trajetória da escolarização de jovens e adultos no Brasil: de plataformas de governo a propostas pedagógicas esvaziadas. Ensaio: Avaliação e Políticas Públicas em Educação, Rio de Janeiro, v. 18, n. 67, p. 389-410, abr./jun. 2010. https://doi.org/10.1590/S0104-40362010000200011

FRIGOTTO, G. Cidadania e formação técnico profissional: desafios neste fim de século. In: SILVA, L. H. et al. (org.). Novos mapas culturais, novas perspectivas educacionais. Porto Alegre: Sulina, 1996. p. 137-164.

GADOTTI, M. Educação popular e educação ao longo da vida. In: NACIF, P. G. S. et al. (org.). Confintea Brasil +6: tema central e oficinas temáticas. Brasília, DF: MEC, 2016. p. 50-69. (Coletânea de textos).

HADDAD, S. A Educação de pessoas jovens e adultos e a nova LDB. In: BRZEZINSKI, I. (org.). LDB interpretada: diversos olhares se entrecruzam. 7. ed. São Paulo: Cortez, 2002. p. 111-127.

HADDAD, S.; DI PIERRO, M. C. Escolarização de jovens e adultos. Revista Brasileira de Educação, Rio de Janeiro, n. 14, p. 108-130, ago. 2000 . 
INSTITUTO NACIONAL DE ESTUDOS E PESQUISAS EDUCACIONAIS ANÍSIO TEIXEIRA - INEP. Sinopse Estatística da Educação Básica 2016. Brasília: Inep, 2017. Disponível em: $<$ http://inep.gov.br/sinopses-estatisticasda-educacao-basica. Acesso em: 15 jun. 2018.

MACHADO, M. M. A Educação de Jovens e Adultos. Após 20 vinte anos da lei $\mathrm{n}^{\circ}$ 9.394, de 1996. Revista Retratos da Escola, Brasília, v. 10, n. 19, p. 429-451, jul./dez. 2016. https://doi.org/10.22420/rde.v10i19.687

MINAYO, M. C. S.; COIMBRA JUNIOR, C. E. A. (orgs.). Antropologia, saúde e envelhecimento. Rio de Janeiro: Editora FIOCRUZ, 2002. (Coleção Antropologia \& Saúde).

MORENO, A. C. Brasil ainda não atingiu meta de redução de analfabetismo fixada para 2015. G1. Educação. 18 maio 2018. Disponível em: https://g1.globo.com/educacao/noticia/brasil-ainda-nao-atingiu-meta-dereducao-de-analfabetismo-fixada-para-2015.ghtml. Acesso em: 5 jun. 2018.

MOTT, L. C. G. O desafio da Educação na Terceira Idade. In: NACIF, P. G. S. et al. (org.). Confintea Brasil +6 : tema central e oficinas temáticas. Brasília: MEC/Secadi, p. 259-267, 2016. (Coletânea de textos).

NERI, A. L. (org.). Idosos no Brasil: vivências, desafios e expectativas na terceira idade. São Paulo: Editora Fundação Perseu Abramo, 2007.

NETO, J. Analfabetismo cai em 2017, mas segue acima da meta para 2015. Agência IBGE Notícias. 18 maio 2018. Disponível em: https://agenciadenoticias.ibge.gov. br/agencia-noticias/2012-agencia-de-noticias/noticias/21255-analfabetismo-cai-em2017-mas-segue-acima-da-meta-para-2015. Acesso em: 28 mar.2019.

ORGANIZAÇÃO MUNDIAL DA SAÚDE - OMS. Relatório mundial de saúde e envelhecimento: resumo. Genebra, 2015.

PAPALÉO NETTO, M.; CARVALHO FILHO, E. T.; SALLES, R. F. N. Fisiologia do envelhecimento. In: CARVALHO FILHO, E. T.; PAPALEO NETTO, M. Geriatria: fundamentos, clínica e terapêutica. 2. ed. São Paulo: Atheneu, 2006. p. 43-92.

PARADELLA, R. Número de idosos cresce $18 \%$ em 5 anos e ultrapassa 30 milhões em 2017. Agência IBGE Notícias. 26 abr. 2018. Disponível em: https://agenciadenoticias.ibge.gov.br/agencia-noticias/2012-agencia-denoticias/noticias/20980-numero-de-idosos-cresce-18-em-5-anos-e-ultrapassa30-milhoes-em-2017. Acesso em: 28 mar. 2019. 
PERES, M. A. C. A andragogia no limiar da relação entre velhice, trabalho e educação. Revista HISTEDBR On-line, Campinas, n. 20, p. 20-27, dez. 2005. https://www.fe.unicamp.br/pf-fe/publicacao/4835/art03_20.pdf

PINTO, A. V. Sete lições sobre educação de adultos. São Paulo: Cortez, 2005.

PORCARO, R. C. Caminhos e desafios da formação de educadores de jovens e adultos. 2011.186f. Tese (Doutorado em Educação) - Universidade Federal de Minas Gerais, Belo Horizonte, 2011.

SANT'ANNA, D. B. Velhice: entre destino e história. Mais 60: Estudos sobre Envelhecimento, São Paulo, v. 27, n. 66, p. 8-19, dez. 2016.

SANTOS, B. F. et al. Identificação das crenças em relação à velhice e ganhos percebidos de professores do CIEJA. Revista Kairós Gerontologia, São Paulo, v. 14, n. 2, p. 119-141, jun. 2011. https://doi.org/10.23925/2176-901X.2011v14i2p119-141

SAVIANI, D. História das ideias pedagógicas no Brasil. Campinas: Autores Associados, 2013.

SERRA, D. C. Gerontagogia dialógica intergeracional para autoestima e inserção social de idosos. Tese Doutorado em Educação) - Universidade Federal do Ceará, Fortaleza, 2012.

SERRA, D. C.; FURTADO, E. D. P. Os idosos na EJA: uma política de Educação inclusiva. Olhar de Professor, Ponta Grossa, v. 19, n. 2, p. 149-161, 2016. https://revistas2.uepg.br/index.php/olhardeprofessor/article/ view/9808/209209210669

SEVERINO, A. J. Metodologia do trabalho cientifico. 24 ed. São Paulo: Cortez, 2016.

SILVA, I. R.; GÜNTHER, I. A. Papéis sociais e envelhecimento em uma perspectiva de curso de vida. Psicologia: Teoria e Pesquisa, v.16, n.1, p. 31-40, jan./abr. 2000. https://doi.org/10.1590/S0102-37722000000100005

SILVA JÚNIOR, J. R. A reforma do estado e da Educação no Brasil de FHC. São Paulo: Xamã, 2002.

UNESCO. Marco de Ação de Belém: aproveitando o poder e o potencial da aprendizagem e educação de adultos para um futuro viável: resumo executivo. Brasília, DF, 2010. 
UNICOVSKY, M. A. R. A educação como meio para vencer desafios impostos aos idosos. Revista Brasileira de Enfermagem, Brasília, DF, v. 57, n. 2, p. 241-243, mar.-abr. 2004. https://doi.org/10.1590/S0034-71672004000200022

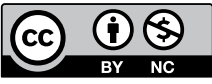

\section{Informações sobre as autoras}

Aparecida da Silva Xavier Barros: Doutoranda do Programa de Pós-Graduação em Educação Matemática e Tecnológica da Universidade Federal de Pernambuco. Professora do Instituto Federal da Paraíba. Contato: aparecidaxbarros@hotmail.com

iD http://orcid.org/0000-0003-1761-7333

Thelma Panerai Alves: Doutora em Inovação Educativa pela Universidad de Deusto, Bilbao, Espanha. Professora do Programa de Pós-Graduação em Educação Matemática e Tecnológica da Universidade Federal de Pernambuco. Contato: tpanerai@gmail.com

(iD) http://orcid.org/0000-0001-5357-5869

Márcia Karina da Silva Luiz: Doutora em Sociologia pela Universidade Federal de Pernambuco. Professora do colegiado permanente do Programa de do Programa de Pós-Graduação em Tecnologia e Gestão da Educação a Distância da Universidade Federal Rural de Pernambuco. Contato: marcialuiz6@gmail.com

iD https://orcid.org/0000-002-0428-9636

Elicia Barros Guerra Souza: Doutoranda do Programa de Pós-Graduação em Educação da Universidade Federal de Pernambuco. Técnica Educacional da mesma universidade. Contato: eliciaguerra@hotmail.com

iD https://orcid.org/0000-0002-3177-635X 